\title{
EVALUATION OF FACTORS FOR DISCONTINUATION OF INTRAUTERINE CONTRACEPTIVE DEVICE AMONG WOMEN IN A TERTIARY CARE CENTER IN JAMMU, INDIA
}

\author{
Zareena Hassan Khan'1, Sameena Akhter², Mubashar Mir³, Shashi Gupta ${ }^{4}$ \\ ${ }^{1}$ Consultant Gynaecologist, Postpartum Center, Department of Gynaecology and Obstetrics, GMC, Jammu, J and K. \\ 2Medical Officer (Anaesthetist), Department of Health, J and K. \\ ${ }_{3}^{3}$ Medical Officer, Department of Health, $J$ and $K$. \\ ${ }^{4}$ Professor and HOD, Department of Gynaecology and Obstetrics, GMC Jammu, J and K.
}

\section{ABSTRACT}

\section{BACKGROUND}

The current contraception is well studied, reliable and available. Adolescents, the most vulnerable group regarding unwanted pregnancy, use low effective contraception method or not at all. Intrauterine Contraceptive Device (IUCD) is the world's most widely used method of reversible birth control. About 1 out of 5 women in reproductive age all over the world use IUCD, while in India, it corresponds to only about 3 in 100 women, copper devices being the most popular.

The aim of the study is to evaluate Intrauterine Contraceptive Device (IUCD) discontinuation rate and its causes and related factors among women attending OPD/family planning clinic.

\section{MATERIALS AND METHODS}

300 women who had an Intrauterine Contraceptive Device (IUCD) inserted during the last 1-5 years were interviewed during their visits to the OPD/family planning clinic at Shri Maharaja Gulab Singh (SMGS) Hospital, Government Medical College, Jammu. Life tables were used to describe the proportion of women who discontinued IUCD at various time intervals. The main outcome measure was IUCD discontinuation.

\section{RESULTS}

The incidence of IUCD discontinuation in the first year following insertion was $17 \%$. Approximately, $26.33 \%$ of the study sample continued using their devices after 5 years. The average duration of IUCD was 36 months. Of the 300 women, $64.70 \%$ discontinued IUCD use because of a desire to conceive, $23.52 \%$ because of side effects, $10.40 \%$ because of opposition from the woman's family and $1.35 \%$ because they were sexually inactive.

\section{CONCLUSION}

The crude cumulative rate of IUCD discontinuation was $17 \%$ during the first year suggesting a need to tackle the problem of discontinuation through effective education strategies and counseling techniques. The average duration of IUCD use in majority of the females was about 36 months. Desire to have a male child predominates among Indian families. There are various misconceptions and myths related to IUCD use, which are needed to be understood and make our society to learn it by education and proper counseling.

\section{KEYWORDS}

Family Planning, IUCD, Discontinuation.

HOW TO CITE THIS ARTICLE: Khan ZH, Akhter S, Mir M, et al. Evaluation of factors for discontinuation of intrauterine contraceptive device among women in a tertiary care center in Jammu, India. J. Evolution Med. Dent. Sci. 2017;6(55):4157-4160, DOI: $10.14260 /$ Jemds/2017/901.

\section{BACKGROUND \\ The current contraception is well studied, reliable and available. Adolescents, the most vulnerable group regarding unwanted pregnancy, use low effective contraception method or not at all. Intrauterine Contraceptive Device (IUCD) is the world's most widely used method of reversible birth control. About 1 out of 5 women in reproductive age all over the world use IUCD, while in India, it corresponds to only about 3 in 100 women, copper devices being the most popular.[1]}

Financial or Other, Competing Interest: None.

Submission 06-06-2017, Peer Review 29-06-2017,

Acceptance 05-07-2017, Published 10-07-2017.

Corresponding Author:

Dr. Zareena Hassan Khan,

House No. 194-A, Ustad Mohalla,

Jammu-180001, J and $K$.

E-mail: zareenahkhan2000@gmail.com

DOI: $10.14260 /$ jemds $/ 2017 / 901$

\section{(c) $(1)$}

It is currently used by nearly 163 million women worldwide accounting for about $15 \%$ of the women in reproductive life.[2] Efforts to increase its effectiveness have led to advances and improvements in the original copper releasing devices to such an extent that presently the failure rates for different models vary between 0.2 to $0.6 \%$. No doubt, IUCD comes in hospital supply under family welfare scheme by Government of India, but it still is largely underutilised. The advantages are understated and the disadvantages and side effects tend to be exaggerated and there are numerous myths and misconceptions, family pressure, improper selection of clients, poor counseling and lack of follow up that led to its ineffective use as contraception. According to National Family Health Survey-3 (NFHS-3), IUCD account for only $1.2-1.6 \%$ of total contraceptive usage in the country.[3] The acceptance can be increased by proper knowledge and up-to-date information of the provider as the side effects of IUCD maybe unpleasant, but are not harmful. 
The main purpose of this study was to evaluate the determinants of IUCD discontinuation among Indian women in this part of the country, so that effective and efficient family planning program can be framed.

\section{MATERIALS AND METHODS}

This study was a hospital-based retrospective descriptive study. Three hundred women visiting OPD/family planning at postpartum center of SMGS Hospital, Government Medical College, Jammu, J and $\mathrm{K}$, who had an IUCD inserted during the last five years at any government or private health facility were recruited from June 2014 to May 2015. The type of IUCD inserted, the method of insertion and type of insertion were determined from the records available with the women. Women with $\mathrm{Cu}-\mathrm{T}$ other than $380 \mathrm{~A}$ who refused to give consent for participation, women with failure or suspected preformation and women with newly-diagnosed medical or gynaecological disease were excluded from the study. A proforma was prepared to be asked and verbal interview and counseling was done consequently in the same sitting followed by the removal of IUCD in those who refused to continue using the same.

The information in the form of marital age, age at IUCD insertion, level of education, total number of pregnancies, number of living children, sex of living children, previous use of contraception methods, previous obstetric history, counseling, client satisfaction and reason for IUCD discontinuation and side effects encountered were collected. Sociodemographic characteristics for all women were described using frequency distribution. Life tables were used to describe the proportion of women who discontinued IUCD at various time intervals. The main outcome measure was IUCD discontinuation.

Data was analysed using open Epi (ver. 3.01). All tests were performed at a level of significance of $5 \%$, thus for an association to be significant, a 'p' value of less than 0.05 was considered. The categorical variables were presented as percentages (\%). The test of association used for qualitative data was Pearson's Chi-square test.

\section{RESULTS}

The incidence of IUCD discontinuation in the first year following insertion was $17 \%$. 79 women out of 300 , i.e. $26.33 \%$ of the study sample continued IUCD after 5 years. $20.48 \%$ had their IUCDS removed after a period of $2-3$ years of insertion. Average duration of IUCD use was 36 months (Table 1).

\begin{tabular}{|c|c|c|c|}
\hline $\begin{array}{c}\text { Time } \\
\text { (Months) }\end{array}$ & $\begin{array}{c}\text { Females who } \\
\text { Discontinued } \\
\text { (n) }\end{array}$ & $\begin{array}{c}\text { No. of Woman } \\
\text { with IUCD } \\
\text { at Start } \\
\text { of Study }\end{array}$ & $\begin{array}{c}\text { \% of Dis- } \\
\text { continuation }\end{array}$ \\
\hline$\leq 12$ & 51 & 300 & $17 \%$ \\
\hline $13-24$ & 62 & 249 & $20.66 \%(24.8)$ \\
\hline $25-36$ & 57 & 187 & $19 \%(30.48)$ \\
\hline $37-48$ & 33 & 130 & $11 \%(25.38)$ \\
\hline $49-60$ & 18 & 97 & $6 \%(18.55)$ \\
\hline$>60$ & & 79 & $26.33 \%$ \\
\hline \multicolumn{2}{|c|}{ Table 1. Time Interval of IUCD Discontinuation } \\
\hline
\end{tabular}

Out of 300 women, $64.70 \%$ discontinued IUCD use because of a desire to conceive, $23.52 \%$ because of side effects mainly pain and bleeding, $10.40 \%$ because of family opposition and $1.35 \%$ because of sexually inactiveness.

The discontinuation in the first 12 months of use was mostly due to side effects like irregular bleeding and menorrhagia followed by infection and pain. The higher discontinuation rates in the second and the third years were chiefly due to the desire of the women to conceive (Table 2). These findings were in agreement with the study conducted by Khader YS et al in Jordan and Sharma Megha et al..[4],[5]

\begin{tabular}{|c|c|c|c|}
\hline \multirow[b]{2}{*}{$\begin{array}{l}\text { Time } \\
\text { (Months) }\end{array}$} & \multicolumn{3}{|c|}{ Reasons of Discontinuation } \\
\hline & $\begin{array}{c}\text { Desire to } \\
\text { Conceive }(\mathrm{N})\end{array}$ & $\begin{array}{c}\text { Side } \\
\text { Effects (N) }\end{array}$ & $\begin{array}{c}\text { Family } \\
\text { Opposition/ } \\
\text { Sexually } \\
\text { Inactive (N) }\end{array}$ \\
\hline$\leq 12$ & 16 & 20 & 12 \\
\hline $13-24$ & 44 & 13 & 9 \\
\hline $25-36$ & 41 & 10 & 2 \\
\hline \multirow[t]{2}{*}{$\geq 37$} & 42 & 9 & 3 \\
\hline & $143(64.7)$ & $52(23.52)$ & $26(11.76)$ \\
\hline \multicolumn{4}{|c|}{$\begin{array}{l}\text { Table 2. Association Between Time } \\
\text { and Reasons of Discontinuation }\end{array}$} \\
\hline
\end{tabular}

$$
\mathrm{X}^{2}=30.76, \mathrm{p}=0.000
$$

Table 2 shows that desire to conceive as reason for discontinuation was more at 13-24 months (30.76\%), whereas those who had side effects or family association/sexual proximity, discontinued at less than 12 months (38.46\% and $46.15 \%$, respectively). The association between time and reasons for discontinuation was statistically highly significant $(\mathrm{p}=0.000)$.

Family opposition mainly from husband was found to be unique variable in our study. This variable was not found to be very significant in study by Khader et al.[5] Our findings were contrast with the study conducted and reported by Mahdy and El-Zeinyin Egypt where discontinuation rate was higher in first year (28\%).[6]

Five patients of $<20$ years of age got their IUCD removed with $100 \%$ discontinuation rate as shown in Table 3 as corroborated with the study by Okunlola MA et al at Ibaden.[7] The rate of discontinuation decreased gradually with the increase in age at insertion with the lowest discontinuation rate $63.63 \%$ at the age of $>40$ years (Table 3 ). 


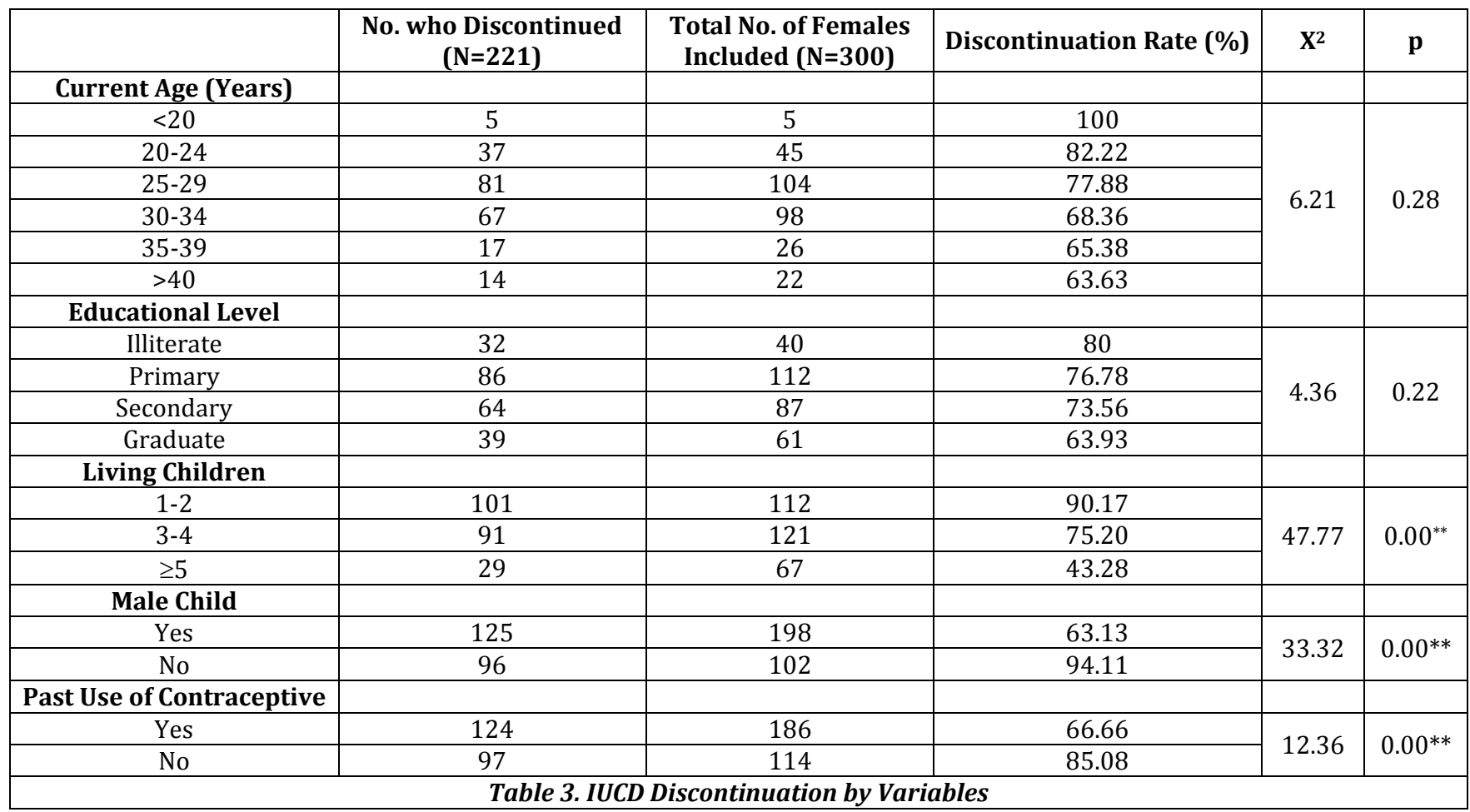

**-Highly Significant.

Table 3 depicts that there was a statistically significant association between having 1-2 living children, having a male child and having used contraceptive in the past with the rate of discontinuation of contraceptives $(\mathrm{p}=0.00,0.00,0.00$, resp.).

Educational status of women and family also has an direct and indirect effect on discontinuation rate of IUCD with the highest rate in illiterate women $(80 \%)$ and lowest among graduates (63.93\%) (Table 3). An improvement in the level of education of women will have direct impact on family planning program who will become receptive to listen facts and myths or misconception related to IUCD.

The discontinuation rate was the highest (90.17\%) among those with 1-2 living issues and decreased with the subsequently higher number of living children. About $94.11 \%$ of women who had no male child discontinued the use of IUCD. Having male child in the family is the unique trend indicating that the desire to have a male child predominates in the mentality of Indian society. This is conflicting with the results obtained in the study from Jordan.[5] While similar results were obtained by Kawsar LA et al in Bangladesh who concluded that the families who have one child of each sex are the most satisfied with their current family composition.

$66.66 \%$ of the females using contraception in any form discontinued IUCD as against $85.08 \%$ among those who had not used the contraception in any past. This is in accordance with the results obtained in Pakistan by Azmat et al. The result also corroborated well with the study by Sharma Megha et al.[4] It indicates that the motivated women desire to have a safe and long lasting contraceptive method. In our study, type of insertion has no significant effect as discontinuation rate as in accordance with study by Sharma Megha et al.[4] $70 \%$ in intracaesarean insertion, $70.4 \%$ in post-abortion insertion and $76.2 \%$ in interval insertion discontinued IUCD use (Table 4).

\begin{tabular}{|c|c|c|c|}
\hline $\begin{array}{l}\text { Period of } \\
\text { Insertion }\end{array}$ & $\begin{array}{l}\text { Total No. of } \\
\text { Insertion }\end{array}$ & $\begin{array}{c}\text { No. of } \\
\text { Removal }\end{array}$ & Percentage \\
\hline Intracaesarean & 30 & 21 & $70 \%$ \\
\hline Post abortion & 98 & 69 & $70.4 \%$ \\
\hline Interval & 172 & 131 & 76.2 \\
\hline Total & 300 & 221 & 73.6 \\
\hline
\end{tabular}

\section{DISCUSSION}

In this study, average duration for which IUCD was continued to be in use was 36 months. $26.33 \%$ continued IUCD after 5 years. The incidence of IUCD discontinuation in the first year following insertion was $17 \%$, mostly due to side effects like irregular bleeding, menorrhagia, infection and pain. 20.48\% had their IUCDS removed after a period of 2-3 years of insertion chiefly due to the desire of the women to conceive. These findings were in agreement with the study conducted by Khader YS et al in Jordan and Sharma Megha et al.[4],[5]

Family opposition mainly from husband was found to be unique variable in our study with $10.40 \%$ discontinuation. This variable was not found to be very significant in study by Khader et al.[5] Our findings were in contrast with the study conducted and reported by Mahdy and El-Zeiny in Egypt where discontinuation rate was higher in first year (28\%).[6]

Five patients of $<20$ years of age got their IUCD removed with $100 \%$ discontinuation rate as corroborated with the study by Okunlola MA et al at Ibaden.[7]

In this study, we found statistically significant association between having 1-2 living children, having a male child and having used contraceptive in the past with the rate of discontinuation of contraceptives.

Educational status of women and family also has a direct and indirect effect on discontinuation rate of IUCD with the 
highest rate in illiterate women (80\%) and lowest among graduates (63.93\%). So, an improvement in the level of education of women will have direct impact on family planning program who will become receptive to listen facts and myths or misconception related to IUCD.

The discontinuation rate was the highest (90.17\%) among those with 1-2 living issues and decreased with subsequently higher number of living children. About $94.11 \%$ of women who had no male child discontinued the use of IUCD. Having male child in the family is the unique trend indicating that the desire to have a male child predominates in the mentality of Indian society. This is conflicting with the results obtained in the study from Jordan. [5] While similar results were obtained by Kawsar LA et al in Bangladesh who concluded that the families who have one child of each sex are the most satisfied with their current family composition. ${ }^{[8]}$

$66.66 \%$ of the females using contraception in any form discontinued IUCD as against $85.08 \%$ among those who had not used the contraception in any past. This is in accordance with the results obtained in Pakistan by Azmat et al.[9] The result also corroborated well with the study by Sharma Megha et al. ${ }^{[4]}$ It indicates that the motivated women desire to have a safe and long-lasting contraceptive method. In our study, type of insertion has no significant effect as discontinuation rate as in accordance with study by Sharma Megha et al.[4]

\section{CONCLUSION}

The average duration of IUD use in a majority of the females was about 36 months, thereby fulfilling its objective of spacing between the children as laid down by WHO (2 years spacing between pregnancies). About $26.33 \%$ of the women continued using IUCD even after 5 years. The discontinuation rate of IUCD was $17 \%$ during the first year suggesting a need to tackle the problem of discontinuation through effective educational strategies and counseling techniques. Modern IUCD are safe, effective and quickly reversible long term contraceptives that require little attention after insertion. Yet safety concerns and programmatic challenges have held back IUCD services in many countries. The most common reasons for voluntary IUCD removal were the women's desire to conceive and the experience of side effects. The commonest side effects were irregular bleeding, menorrhagia and pain. Discontinuation was inversely related to age and education of female. Desire for conceiving a male child also has an effect on discontinuation rate of IUCD.

Government shall provide information regarding family planning services using mass media, family planning workers, multipurpose workers like Asha and establishment of family planning health centers. Encouraging husbands to learn more about the possible benefits on IUCD use will make a difference. Clearing and counseling about myths and misinterpretation are very important task to be done by healthcare providers. Social and religious factors are to be kept in mind and involvement of religious leaders to improve the health status of women should be the part of counseling and awareness creating programs.

\section{REFERENCES}

[1] Piego JH. IUD guidelines for family planning service program, USAID 2006.

[2] Salem RM. New attention to the IUD: expanding women's contraceptive options to meet their needs. Popul Rep B 2006; 7:1-26.

[3] International Institute for Population Sciences (IIPS) and Macro International 2007. National Family Health Survey (NFHS-3), India: Volume-I. 2005-06.

[4] Megha S, Shubham J, Akash S, et al. Determinants of intrauterine contraceptive device discontinuation among Indian women. J Obstet Gynaecol 2014;64(3):208-11.

[5] Khader YS, El-Qaderi S, Khader AM. Intrauterine contraceptive device discontinuation among Jordanian women: rate, causes and determinants. J Fam Plann Reprod Health Care 2006;32(3):161-4.

[6] Mahdy NH, el-Zeiny NA. Probability of contraceptive continuation and its determinants. East Mediterr Health J 1999;5(3):526-39.

[7] Okunlole MA, Owonikoko KM, Roberts OA, et al. Discontinuation pattern among IUCD users at the family planning clinic, university college hospital, Ibadan. J Obstet Gynaecol 2006;26(2):152-6.

[8] Kawsar LA, Kabir A, Islam MA. Sex preference and contraceptive norms among regions in Bangladesh. Int Q Community Health Educ 2008-2009;29(2):183-97.

[9] Azmat SK, Shaikh BT, Hameed W, et al. Rates of IUCD discontinuation and its associated factors among the clients of a social franchising network in Pakistan. BMC Womens Health 2012;12:8. 